\title{
The First Case of Acute Neonatal Suppurative Parotitis Caused by Escherichia coli in Korea
}

Jae Young Cho, $\mathrm{MD}^{1}$, Jong Hyuk Youn, $\mathrm{MD}^{1}$, Ji Sook Park, $\mathrm{MD}, \mathrm{PhD}^{1}$, and Jae Min Cho, $\mathrm{MD}, \mathrm{PhD}^{2}$

Departments of ${ }^{1}$ Pediatrics and ${ }^{2}$ Radiology, Gyeongsang National University Hospital, Jinju, Korea

\section{ABSTRACT}

Neonatal acute suppurative parotitis is rare. Staphylococcus aureus is the most common pathogen and antibiotic treatment is the first line therapy. Here, we report a case of acute suppurative parotitis caused by Escherichia coli in a 7-day-old male with febrile sensation, parotid swelling, and purulent discharge from the Stensen duct who was treated successfully with intravenous antibiotics. To the best of our knowledge, this is the first case of neonatal suppurative parotitis caused by E. coli in Korea.

Key Words: Suppuration; Parotitis; Newborn; Escherichia coli

\section{INTRODUCTION}

Acute suppurative parotitis is rare in neonates with a rate of 13.8 per 10,000 admissions ${ }^{1)}$. It was considered a vanishing disease ${ }^{2)}$; however, cases have been reported sporadically within literature since $1970^{3}$. Prematurity and dehydration have been reported as major risk factors of neonatal suppurative parotitis ${ }^{3)}$. Diagnosis is made clinically and parotid swelling and purulent discharge from the Stensen duct are both pathognomonic ${ }^{4}$. Staphylococcus aureus is the most common pathogen ${ }^{3}$. Antibiotic therapy is the treatment of choice and prognosis is usually good with rare cases of recurrence ${ }^{3-5)}$. The authors experienced a case of acute neonatal suppurative parotitis caused by Escherichia coli in a 7-day-old male. To the best our knowledge, this is the first reported case of acute neonatal suppurative parotitis caused by $E$. coli in Korea.

\section{CASE REPORT}

A 7-day-old breast milk-fed male was transferred from an outside hospital due to acute swelling of the left cheek and febrile sensation. He was born at 37 weeks of gestation by spontaneous vaginal delivery after an uneventful pregnancy. The patient's birth weight was 2,980 $\mathrm{g}$ and Apgar scores were 9 at 1 minute and 10 at 5 minutes after birth. Upon admission,
Received: 4 March 2020

Revised: 20 April 2020

Accepted: 25 April 2020

Correspondence to: Ji Sook Park, MD, $\mathrm{PhD}$

Department of Pediatrics, Gyeong. sang National University Hospital, 79 Gangnam-ro, Jinju 52727, Korea

Tel: +82-55-750-8156

Fax: +82-55-752-9889

E-mail: csassi@hanmail.net

Copyright(c)

By Korean Society of Neonatology.

All right reserved.

This is an Open-Access article distributed under the terms of the Creative Commons At tribution Non-Commercial License (http:// creativecommons.org/licenses/by-nc/4.0), which permits unrestricted non-commercial use, distribution, and reproduction in any medium, provided the original work is properly cited. 
the infant's weight was 2,880 g, rectal temperature was $37.4^{\circ} \mathrm{C}$, and vital signs were stable. On physical examination, the patient had an asymmetric face with a swollen left cheek with approximately $3 \times 4 \mathrm{~cm}$ erythematous swelling with tenderness and heating sensation overlying the left cheek and preauricular area (Figure 1A). Purulent discharge from the left Stensen duct was presented when pressure was applied to the left parotid gland (Figure 1B) which was sent for examination. The remainder of the physical examination were unremarkable. There were no enlarged lymph nodes or hepatosplenomegaly present. Laboratory tests revealed hemoglobin of $16 \mathrm{~g} / \mathrm{dL}$, white blood cell (WBC) count of 14,650 / $\mathrm{mm}^{3}$ (53.8\% neutrophils and $34.6 \%$ lymphocytes), platelet count of $302,000 / \mathrm{mm}^{3}$, C-reactive protein (CRP) was $11 \mathrm{mg} / \mathrm{dL}$ (normal range, 0 to 5), and amylase was $28 \mathrm{U} / \mathrm{L}$ (normal range, 30 to 100). Serum electrolytes were as follows: sodium $137.3 \mathrm{mmol} / \mathrm{L}$; potassium $4.4 \mathrm{mmol} / \mathrm{L}$; chloride $106.3 \mathrm{mmol} / \mathrm{L}$; and total $\mathrm{CO}_{2}$ $18 \mathrm{mmol} / \mathrm{L}$. The results of venous blood gas analysis were as follows: $\mathrm{pH}$ 7.36; $\mathrm{PCO}_{2} 33 \mathrm{~mm} \mathrm{Hg} ; \mathrm{PO}_{2} 37 \mathrm{~mm} \mathrm{Hg}$; bicarbonate $18 \mathrm{mEq} / \mathrm{L}$; and base excess $-6.5 \mathrm{mEq} / \mathrm{L}$. Urinary specific gravity was measured at 1.005. Prothrombin time was 13.9 seconds (normal range, 10 to 16) and activated partial thromboplastin time was 39.5 seconds (normal range, 31 to 54). Serologic analyses for cytomegalovirus, herpes virus, toxoplasmosis, rubella, and mumps were all negative. Ultrasonography (USG) was performed to exclude structural abnormalities or abscess formation in the parotid glands. USG revealed a markedly enlarged left parotid gland with increased vascularity (Figure 2). Given the swollen cheek with inflammatory signs, pus from the left Stensen duct, and the results from the USG, acute suppurative neonatal parotitis was then diagnosed. Intravenous antibiotics of ampicillin/sulbactam (50 mg of ampicillin/kg/day) and gentamicin (4 mg/ $\mathrm{kg} /$ day) were initiated. Purulent discharge from the left Stensen duct yielded growth of $E$. coli with susceptibility to 16 antibiotics tested including ampicillin, cefazolin, imipenem, gentamicin, and amikacin. Blood, urine, and cerebrospinal fluid cultures were negative. The left parotid swelling improved within 2 days and antibiotic therapy was continued for 14 days. USG of both parotid glands was performed after 7 days of antibiotic treatment and showed that the left parotid gland had decreased in both size and vascularity. The patient was discharged from the hospital after 14 days without complication. The patient has been well for 1 year without recurrence.
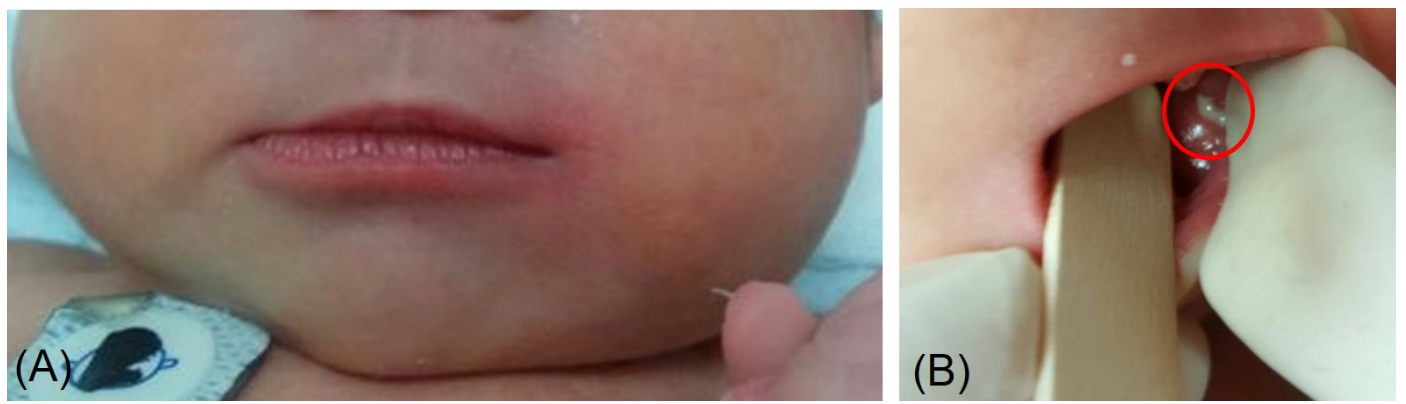

Figure 1. (A) A 7-day-old male revealed asymmetric face and diffuse left cheek swelling and erythema. (B) Purulent discharge was drained from the left Stensen duct (red circle) when the left parotid gland was pressed.
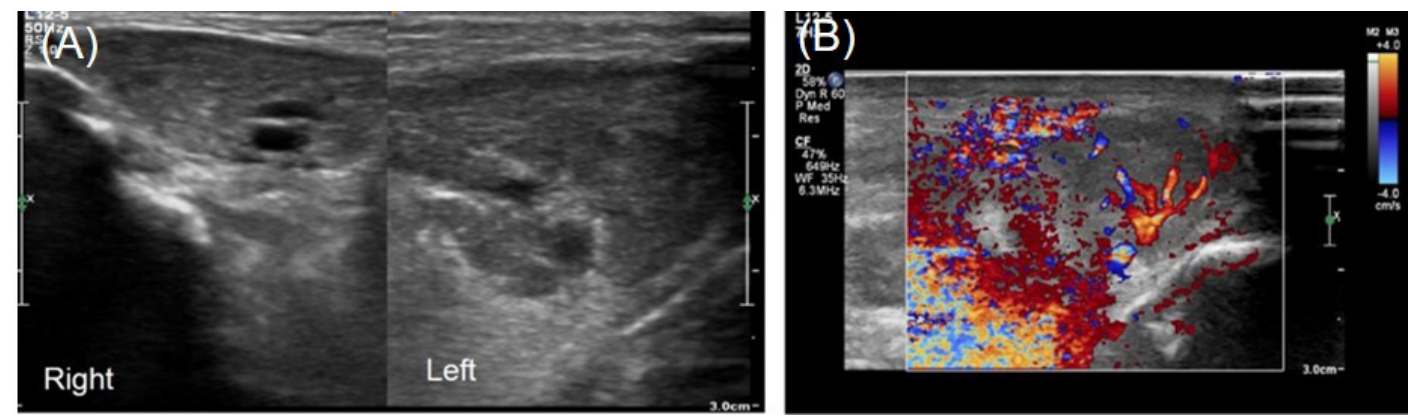

Figure 2. Ultrasonography revealed (A) marked enlargement and (B) increased vascularity of left parotid gland. 


\section{DISCUSSION}

Acute neonatal suppurative parotitis is rare and approximately 50 cases have been reported sporadically globally since 1970 (Table 1$)^{3-12)}$. Male predominance (38/53) and unilateral parotid gland involvement (43/53) are characteristics of neonatal suppurative parotitis. Each parotid gland is evenly involved (right: left, 14:15). The disease occurs a mean of 17.3 \pm 10.5 days after birth (median 17 days; range, 3 to 33). Diagnosis is based on parotid gland swelling, pus drainage from the Stensen duct, and the growth of microorganisms ${ }^{1)}$. The current case was a 7-day-old male with left parotid gland involvement presenting as left parotid gland swelling, pus from the left Stensen duct, and the growth of E.coli in pus culture, which fulfilled the diagnostic criteria. Laboratory investigations have been generally non-specific. Leukocytosis above $15,000 / \mathrm{mm}^{3}$ was seen in $69 \%$ of cases and elevated serum amylase was shown in $25 \%$ of cases $^{4}$. In this case, WBC count was $14,650 / \mathrm{mm}^{3}$ (53.8\% neutrophils and $34.6 \%$ lymphocytes) and CRP was slightly elevated at $11 \mathrm{mg} / \mathrm{dL}$. Serum amylase was $28 \mathrm{U} / \mathrm{L}$ on admission and there was no increase during hospitalization. This may be associated with low activity of salivary isoamylases in infancy ${ }^{13)}$. Serologic tests were beneficial for the differentiation of infectious causes, including mumps, cytomegalovirus, tuberculosis, and human immunodeficiency virus (HIV). In this case, mumps and cytomegalovirus immuno globulin G (IgG) and IgM were negative. Tuberculosis and HIV infection were excluded by previous maternal tests.

Trauma, lymphadenitis, hemangioma, tumor, parotid duct anomalies, and intraglandular abscess formation should be considered and USG of the parotid glands may facilitate differentiating suppurative parotitis from the differential diagnoses ${ }^{6,7)}$ USG of both parotid glands was performed twice in this case.

Table 1. Clinical Characteristics and Isolated Pathogens in the Reported Case of Acute Neonatal Suppurative Parotitis

\begin{tabular}{|c|c|c|c|c|c|c|c|c|}
\hline Study & $\begin{array}{l}\text { No. of } \\
\text { cases }\end{array}$ & Prematurity & $\begin{array}{l}\text { Onset (days } \\
\text { after birth) }\end{array}$ & Male & Involved sites & Antibiotics & Surgery & Pathogens \\
\hline $\begin{array}{l}\text { Spiegel et al. } \\
(2004)^{3)}\end{array}$ & 32 & 11 & $7-30$ & 23 & $\begin{array}{l}5 \text { Bilateral, } 7 \text { right, } 7 \\
\text { left, } 13 \text { undefined }\end{array}$ & Cloaxicillin and gentamicin & 7 & $\begin{array}{l}18 \text { S. aureus, } 11 \mathrm{G}(+)^{*}, 9 \mathrm{G} \\
(-)^{\dagger}\end{array}$ \\
\hline $\begin{array}{l}\text { Ismail et al. } \\
\qquad(2013)^{4)}\end{array}$ & 12 & 2 & $3-20$ & 11 & $\begin{array}{l}4 \text { Bilateral, } 3 \text { right, } 4 \\
\text { left, } 1 \text { undefined }\end{array}$ & $\begin{array}{l}\text { Cloxacillin and cefotaxime/ } \\
\text { vancomycin and gentamicin }\end{array}$ & 3 & $\begin{array}{l}9 \text { S. aureus, } 1 \text { Pseudomonas } \\
\text { aeruginosa }\end{array}$ \\
\hline $\begin{array}{l}\text { Costa et al. } \\
(2016)^{5)}\end{array}$ & 1 & 0 & 8 & 1 & Left & Vancomycin and cefotaxime & 0 & S. aureus \\
\hline $\begin{array}{l}\text { D'Souza et al. } \\
(2012)^{6)}\end{array}$ & 1 & 1 & 20 & 0 & Right & Vancomycin & 0 & Enterococci, MSSA \\
\hline $\begin{array}{l}\text { Deepak et al. } \\
(2015)^{7)}\end{array}$ & 1 & 1 & 27 & 1 & Bilateral & Ceftriaxone and amikacin & 0 & E. coli \\
\hline $\begin{array}{l}\text { Megged et al. } \\
(2018)^{8)}\end{array}$ & 1 & 0 & 6 & 1 & Right & Amoxycillin-clavulanic acd & 0 & MSSA, Streptococcus mitis \\
\hline $\begin{array}{l}\text { Avcu et al. } \\
\qquad(2015)^{9)}\end{array}$ & 1 & 0 & 33 & 0 & Right & Cefotaxime/teicoplanin & 0 & S. aureus \\
\hline $\begin{array}{l}\text { Hamid et al. } \\
\qquad(2014)^{10)}\end{array}$ & 1 & 0 & 18 & 0 & Left & Amoxycillin and clavulanate & 1 & S. aureus \\
\hline $\begin{array}{l}\text { Kadam et al. } \\
\qquad(2017)^{11)}\end{array}$ & 1 & 0 & 9 & 0 & Right & Vancomycin and meropenem & 1 & Pseudomonas aeruginosa \\
\hline $\begin{array}{l}\text { Kolekar et al. } \\
\qquad(2016)^{12)}\end{array}$ & 1 & 0 & 25 & 0 & Left & Cefotaxime to vancomycin & 0 & MRSA \\
\hline Current case & 1 & 0 & 7 & 1 & Left & $\begin{array}{l}\text { Ampicillin/sulbactam and } \\
\text { gentamicin }\end{array}$ & 0 & E. coli \\
\hline Total & 53 & 15 & $\begin{array}{c}17 \\
\text { (median) }\end{array}$ & 38 & $\begin{array}{l}10 \text { Bilateral, } 14 \text { right, } \\
15 \text { left }\end{array}$ & & 12 & \\
\hline
\end{tabular}

${ }^{*} \mathrm{G}(+)$ : Streptococcus viridans 4, Streptococcus pyogenes 2, coagnualse negative staphylococci 2, Streptococci (unspecified) 1, Moraxella catarrhalis 1 , peptostreptococcus $1 ;{ }^{\dagger} \mathrm{G}(-)$ : Escherichia coli 2, Klebsiella pneumonia 2, Pseudomonas aeruginosa 1, Bacteroides 2, Prevotella 2. Abbreviations: S. aureus, Staphylococcus aureus; MSSA, methicillin sensitive S. aureus; E. coli, Escherichia coli; MRSA; methicillin-resistant S. aureus. 
Initial USG revealed an enlarged left parotid gland with increased vascularity compared with the right (Figure 2). The second USG on the seventh day of admission confirmed improvement in the swelling and vascularity of left parotid gland and helped to rule out hemangioma, tumor, or parotid duct stenosis.

Prematurity, dehydration, ductal obstruction, and structural abnormalities of the parotid gland are all risk factors of acute neonatal suppurative parotitis ${ }^{3,8}$. Risk factors contribute to ascending infection through the Stensen duct after bacterial colonization of the oral cavity, and hematogenous spreads as part of septicemia ${ }^{4)}$. Since the parotid glands contain bacteriostatic material, they are more vulnerable to infection than the other salivary glands. In premature infants, suppurative parotitis is more frequent due to prolonged hospitalization, trauma of the oral cavity by tube feeding, and dehydration. Dehydration, ductal obstruction, or structural abnormalities can cause stasis or decreased production of saliva and contribute to develop suppurative parotitis ${ }^{9)}$. In this case, the patient was born at 37 weeks of gestation with weight of 2,980 g. The patient's weight was 2,880 g on admission and he was unable to recover his initial weight on the 7th day of life. Dehydration and consequent retention of saliva contributed to development of the disease ${ }^{6)}$.

The most common pathogen for acute neonatal suppurative parotitis is S. aureus (55.2\%), followed by Gram-positive (22.4\%), Gram-negative organisms (22.4\%), and anaerobes (8.6\%) (Table 1). E. coli is a less common pathogen in this disease. To the best our knowledge, this is the fourth case reported of neonatal sup purative parotitis caused by E. coli globally and the first case in Korea $^{3,7)}$

Given the bacterial spectrum, an antibiotic combination of an anti-staphylococcal agent and an aminoglycoside is appropriate for treatment ${ }^{3)}$. In this case, ampicillin/sulbactam and gentamicin were initiated, and E. coli obtained from the patient was susceptible to both antibiotics. Rehydration was started simultaneously with antibiotics to recover the patient's dehydration and salivary stasis. Antibiotic treatment continued for 14 days with complete recovery.

Most patients with neonatal suppurative parotitis are treated successfully with antibiotics but several cases with complications have been reported to require surgical treatment $t^{3,4,10,11)}$. Potential complications, such as osteomyelitis of the mandible or temporomandibular joint, thrombophlebitis of the jugular vein, respiratory obstruction, and sepsis, should be considered in neo nates with suppurative parotitis and a worsening condition ${ }^{6}$.
Facial palsy has been reported as a complication ${ }^{11)}$, but prognosis is generally good with the appropriate parenteral antibiotic therapy. Acute neonatal suppurative parotitis is rare but easy to diagnose. Immediate and appropriate antibiotic combination therapy is required for rapid clinical recovery and the prevention of complications.

\section{ARTICLE INFORMATION}

\section{Ethical statement}

This case report was reviewed and approved by the Institutional Review Board of Gyeongsang National University Hospital (GNUH 2018-09-019). Informed consent was waived by the board.

\section{Conflicts of interest}

No potential conflict of interest relevant to this article was reported.

\section{Author contributions}

Conception or design: J.S.P.

Acquisition, analysis, or interpretation of data: J.Y.C., J.H.Y., J.M.C.

Drafting the work or revising: J.Y.C., J.S.P.

Final approval of the manuscript: J.S.P., J.M.C.

\section{ORCID}

Jae Young Cho https://orcid.org/0000-0002-3654-067X

Ji Sook Park https://orcid.org/0000-0002-4704-2246

\section{Acknowledgments}

None

\section{REFERENCES}

1. Sabatino G, Verrotti A, de Martino M, Fusilli P, Pallotta R, Chiarelli F. Neonatal suppurative parotitis: a study of five cases. Eur J Pediatr 1999;158:312-4.

2. Coban A, InceZ, Ucsel R, Ozgeneci A, Can G. Neonatal suppurative parotitis: a vanishing disease? Eur J Pediatr 1993;152:1004-5.

3. Spiegel R, Miron D, Sakran W, Horovitz Y. Acute neonatal suppurative parotitis: case reports and review. Pediatr Infect Dis J 2004;23:76-8. 
4. Ismail EA, Seoudi TM, Al-Amir M, Al-Esnawy AA. Neonatal suppurative parotitis over the last 4 decades: report of three new cases and review. Pediatr Int 2013;55:60-4.

5. Costa L, Leal LM, Vales F, Santos M. Acute parotitis in a newborn: a case report and review of the literature. Egypt J Otolaryngol 2016;32:236-9.

6. D'Souza JN, Geary C, Mukerji S. Neonatal parotid gland enlargement: is it suppurative parotitis? A case report. Am J Case Rep 2012;13:41-3.

7. Deepak K, Garima G, Jhamb U. Bilateral acute neonatal suppurative parotitis: a rare finding in neonatal age. J Neonatal Perinatal Med 2015;8:63-5.

8. Megged O, Baskin E. Neonatal parotitis. J Pediatr 2018;196:319.
9. Avcu G, Belet N, Karli A, Sensoy G. Acute suppurative parotitis in a 33-day-old patient. J Trop Pediatr 2015;61:218-21.

10. Hamid R, Shera HA, Khurshid S, Bhat AN, Baba AA, Akhter A. Suppurative parotitis and submandibular sialadenitis. J Clin Neonatol 2014;3:39-40.

11. Kadam RM, Prasad V, Boda S. Acute neonatal suppurative parotitis with facial palsy and pneumonia. Indian J Neonatal Med Res 2017;5:NC01-3.

12. Kolekar S, Chincholi TS, Kshirsagar A, Porwal N. Acute neonatal parotid abscess: a rare case report. Afr J Paediatr Surg 2016;13:199-201.

13. Skude G. Sources of the serum isoamylases and their normal range of variation with age. Scand J Gastroenterol 1975;10:57784. 